Document downloaded from:

http://hdl.handle.net/10251/151159

This paper must be cited as:

Robles-Mateo, E.; Serquera, J.; Lloret Romero, MN.; Sastre, J. (2018). Soundcool Project: Collaborative Music Creation. Advances in Intelligent Systems and Computing. 715:416-420. https://doi.org/10.1007/978-3-319-73210-7_50

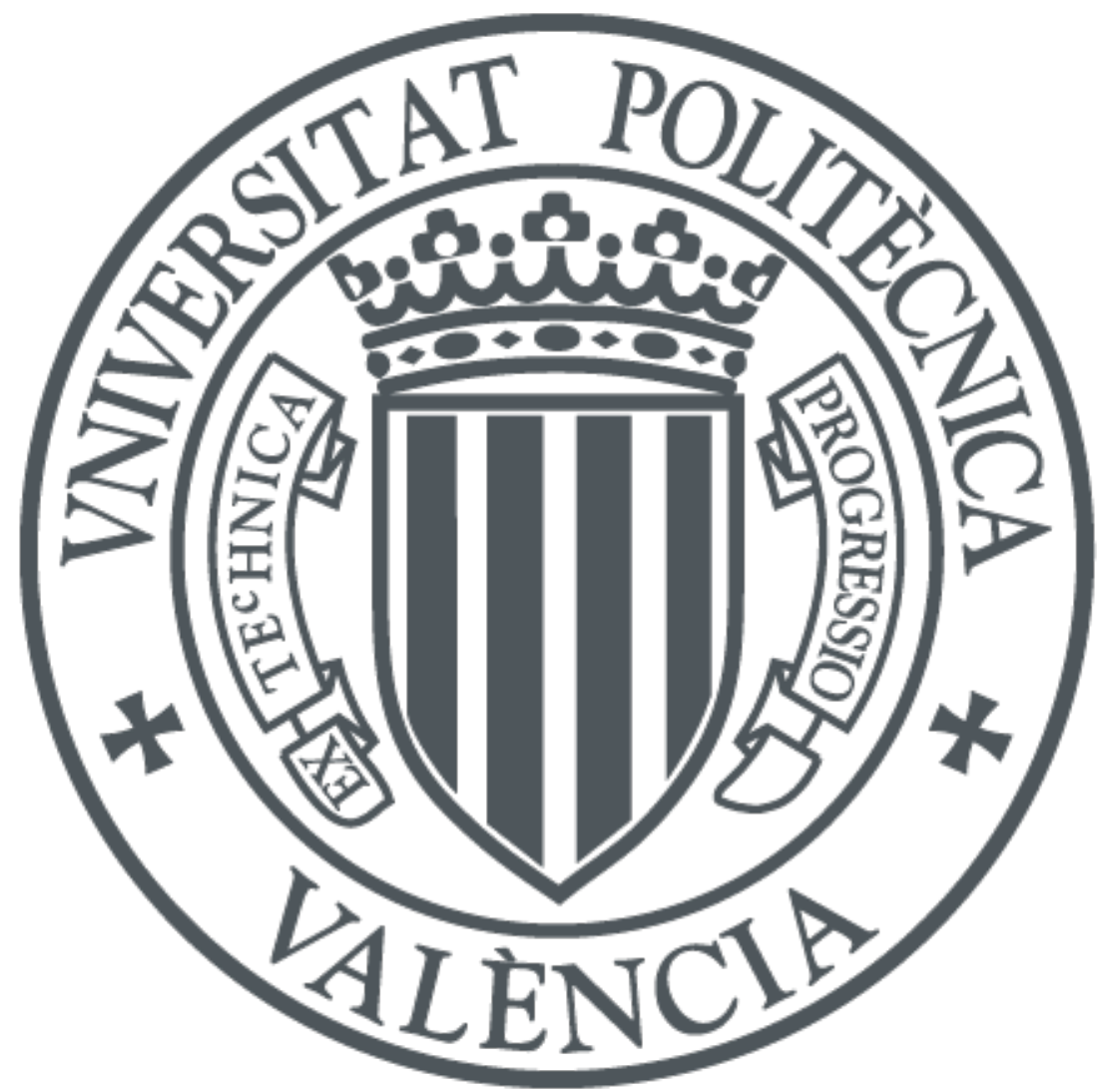

The final publication is available at

https://doi.org/10.1007/978-3-319-73210-7_50

Copyright Springer

Additional Information 


\title{
Soundcool Project: Collaborative Music Creation
}

\author{
Elena Robles Mateo, Jaime Serquera, Nuria Lloret Romero, Jorge \\ Sastre Martínez \\ IDF-iTEAM, Universitat Politècnica de València, Valencia, Spain \\ elrobma@bbbaa.upv.es
}

\begin{abstract}
This paper addresses four criteria that the Soundcool project meets: to "be sustainable", "be future-oriented", "be transformative" and "be innovative". Soundcool is a pedagogical and technological project. A brief description of the technology behind Soundcool will be useful for the reader before addressing the four criteria. Soundcool is like a "Lego" for sound; Soundcool is composed of a series of software modules that run on a central computer, or host computer. Each module is sort of a musical instrument; it could be a synthesizer, a sampler, a sound effect processor, etc. these modules can be interconnected in different ways allowing the users, i.e. the students, to create their own arrangements, as we call the module creations and interconnections. Then, each module can be controlled either with the mouse or, what is more interesting, with a mobile device through WiFi. This way, every student can control one or several modules of the whole arrangement from their mobile device contributing to a collaborative and participative experience.
\end{abstract}

Keywords-collaborative creation, sound creation, modules, innovative, transformative, sustainable, future-oriented education, music education, pedagogic, Kinect, MAX-MSP, mobile devices, tablets

\section{Soundcool Project}

\subsection{Soundcool is Sustainable}

Soundcool is sustainable from two perspectives, the technical and the pedagogical. Regarding software, sustainability can refer to different concepts, one of which is being a long-lasting program. This is the case of Soundcool for several reasons. The project began in 2013 and today, in 2017 we are still doing amazing activities with students outside the classrooms. For example a recent Soundcool performance was carried out at the TEDxUPValència event held in February 2017 in Valencia, Spain. The Soundcool software will be maintained in the future because, in spite of being a free software, the technical university where it is developed, the Universitat Politècnica de València (UPV, Spain), can provide a great number of motivated students to carry out their final projects or internships within the Soundcool team. We always have young people interested in doing technological developments for this project. We have managed to maintain the software for Windows and Mac, adapting it 
to new versions every year. Apart from maintenance, we are also constantly including new features.

Since music is a universal language, Soundcool is also global, and its characteristics allows it to be used by any community in the World. In the future, when more users will adopt Soundcool, we are planning to adopt a similar sustainable model to that of the famous audio software Audacity (http://www.audacityteam.org/). And we are confident we will be able to implement it successfully because the co-creator, Prof. Roger Dannenberg, is an active collaborator of Soundcool from the very beginning of the project. Soundcool was born in 2013 with a UPV research project and a Spanish ministry grant for Dr. Jorge Sastre to visit CMU as a researcher at Dannenberg's group. In this visit Dr. Sastre discussed with Dannenberg about the conception of Soundcool and gave the first talks about the system at CMU (Pittsburgh, USA).

Soundcool is sustainable also because it does not require expensive equipment. Any computer can run Soundcool on its own with a mouse and speakers. The use of smartphones and tablets is optional, and they can be inexpensive Android phones or tablets which the students already own, and iOS devices are also allowed.

\subsection{Soundcool is Future-Oriented}

The school of the $21^{\text {st }}$ century opens the doors to the technological progress more and more every day. This advancement has to go hand-in-hand with pedagogical approaches and didactic strategies that allow our kids and teens to integrate the learning process in an innovative, functional, social and competent way. In this sense, Soundcool is a tool capable of developing creative and artistic thinking, and thus, the students can manage skills at the level of divergent thinking, which is essential when our aspirations are, for example, to develop active citizens as well as to train the future entrepreneurs of our society.

The incorporation of new technologies for music education at primary and secondary levels opens up great possibilities to improve the teaching and learning processes. New interfaces for human-computer interaction such as multi-tactile surfaces, smartphones, tables and also systems for collaborative creation represent promising tools to improve the motivation and the interest of the students, to develop their cognitive skills and to support the educational process. However, still nowadays in many countries, the most extended kind of music education continues to be entrenched in the traditional musical language and the conventional use of instruments commonly found in the classroom, such as the recorder, within a system where classes are mainly traditional lectures with little discussion or participation of the students. In this sense, Soundcool is future-oriented since it is based on the use of mobile devices by the students. Tactile devices allow direct manipulation of objects and controls by means of multi-tactile interactions with excellent results in electronic musical instrument design and also in educational projects in general. Additionally, these devices are in fact already part of our daily life. The worldwide mobile phone market has followed a remarkable trend and it will continue growing in the following years according to reports of the International Data Corporation (IDC). The number of mobile devices has already overcome the number of all humans.

Soundcool is also future-oriented because it includes pedagogical work and technical developments for people with special educational needs. It is believed that the level of development of a society can be estimated by how it deals with disabled people. The 
societies of the future will be more and more inclusive every day. In this sense, Soundcool team's aim is the training of music teachers, therapists, relatives and everyone who works and shares their lives with persons with functional diversity using music as an educational and motivational tool. This is why a research group has emerged inside Soundcool's team. It is called Emosons (from emotion and sound) and it focuses on pedagogical and music-therapy developments and also aims at addressing the usability and implementation of the Soundcool application in groups with functional diversity, to introduce the application as a therapeutic tool in the set of playful and creative activities of the "La Torre Occupational Centre" (Valencia, Spain), where the tests are currently being conducted.

\subsection{Soundcool is Transformative}

Soundcool has an enormous potential to transform education worldwide, in a universal way, by offering an education for all. Its easiness of transference allows for its replication in different parts of the world. Soundcool can be used by any person regardless of their cultural and socio-economical level, by using low-cost smartphones and PCs or recycled ones. Ongoing investigations show that the use of Soundcool is equally satisfactory by both participant groups of people with music knowledge and people with no musical training. Therefore, the system allows any user to express creatively without a previous specialized training.

Soundcool has the capacity of breaking physical barriers and transforms the spatial sense of places for sound-art creation; beyond the traditional classroom, Soundcool encourages experimentation transcending boundaries, global on-line work, and the use of "lab" environments that generate spaces for learning based on experimentation. This technology will generate significant changes in the music education area. On the Soundcool website we are designing a collaborative environment (http://network.soundcool.org) to facilitate the exchange of ideas and creations of all the users.

We are seeing by ourselves how teachers are transforming their view towards music education in the courses and workshops that we are delivering across all of Spain and the countries that participate in the Erasmus+ European project (explained below) such as Portugal, Italy and Romania. We know that apart from the technical aspects of Soundcool, a change in the mentality is necessary regarding the didactic methodologies and teaching and learning approaches. In relation to teacher training, our interest is focused on the development of creative strategies that boost a new approach from a new paradigm that sees the students as creators and not simply as information receptors. In this sense, Soundcool has been presented by the authority responsible for education in the Valencia Community (Spain) as a promising system that can help develop the competencies needed for the education of our students in the foreseeable future.

Soundcool is also transforming the practical activities of the students at Primary and Secondary levels. With Soundcool they take part in concerts outside the classroom in auditoriums and other public venues like the Principal Theatre or the Palau de les Arts in Valencia (Spain), which is a great complementary activity for their education. In the TEDxUPValencia event on Feb. 17, 2017 Soundcool was presented and the students performed the piece Metropolis, based on the sounds of the city. In addition, a large-scale Opera entitled "La Mare dels Peixos" ("the Mother of the Fish") has 
been premiered at the Opera House of Valencia, "Palau de les Arts", on 16th Dec., 2016.

The above mentioned Erasmus+ European project has also contributed to transform the education using Soundcool. The project is a European strategic partnership for school education KA2: "Technology for learning and creativity: weaving European networks through collaborative music creation" involves seven organizations in the field of education and culture from Spain, Portugal, Italy and Romania (primary, secondary and music schools). This project emerges from a vision to use arts education and especially music education to transform the classroom by incorporating new methodologies based on Soundcool system in order to enhance the development of skills needed for the twenty first century society such as creativity, digital literacy, cultural and linguistic competence and team work.

\subsection{Soundcool is innovative}

The Souncool innovative contribution to education has been recognized with several prizes. We have to say that, although what we propose is a total paradigm shift and involves a profound transformation in the ways of teaching music in classrooms, it is not our intention to break with tradition, but rather to expand the possibilities and the sound palette and thus the music education.

Pedagogically, Soundcool is based on placing students at the center of learning, giving them the opportunity to be the creators of their own creations. These ways of "learning from doing" and learning between equal individuals are in perfect agreement with the latest advances in theories of learning. The teacher's role as a totem shifts towards a much more horizontal view of learning. Now the teacher's role has to be that of a facilitator and builder of creative spaces.

Expanding teaching music based on music history and playing traditional instruments, Soundcool allows the creation of an entire orchestra of the $21^{\text {st }}$ century through mobile devices. The ability to imagine new sound universes is now infinite.

\section{Acknowledgements}

This work is supported by Daniel \& Nina Carasso Foundation, project 16-AC-2016 and Cátedra Telefónica-UPV 2016-17.

\section{Bibliography}

J. Sastre, J. Cerdà, W. García, C.A. Hernàndez, N. Lloret, A. Murillo, D. Picó, J.E. Serrano, S. Scarani, R.B. Dannenberg, New Technologies for Music Education, in Proc. of the 2nd Int. Conf. on e-Learning and e-Technologies in Education (ICEEE), Ed. IEEE, 2013, pp. 149-154.

M. Wright, The Open Sound Control 1.0 Spec., V. 1.0, March 26, 2002, http://opensoundcontrol.org/

A.T. Regelski, Music and Music Education: Theory and Praxis for 'Making a Difference, in D.K. Lines (ed.), Music Education for the New Millennium: Theory and Practice Futures for Music Teaching and Learning, Malden, Blackwell Publishing, 2005.

S. Nicolls, Seeking Out the Spaces Between: Using Improvisation in Collaborative Composition with Interactive Technology, Leonardo Music Journal vol. 20, 2010, pp. 47-55. 
A. Miranda, G. Santos \& S. Stipicich, Algunas características de investigaciones que estudian la integración de las TIC en la clase de ciencia (Some characteristics of research exploring the integration of ICT in science class), in Revista Electrónica de Investigación Educativa, 12(2), 2010, from

http://redie.uabc.mx/index.php/redie/article/View/259

M.E. Almirón \& S. Porro, Las Tic en la enseñanza: un análisis de casos (ICT in education: an analysis of cases), in Revista Electrónica de Investigación Educativa, 16(2), 2014, pp.152-160.

V. Zabala \& L. Arnau, Métodos para la enseñanza de las competencias (Methods for teaching of skills), Barcelona, Graó, 2014.5981 